\title{
Application of Spatial Analysis to Identify the Location of Entrepreneurs Supported by the Regional Government in Andalusia (Spain)
}

\author{
Maria Luisa Rodero-Cosano ${ }^{1}$ (D) - Araceli de los Ríos-Berjillos ${ }^{2}$. \\ Salud Millán-Lara ${ }^{3}$ Y Yolanda Muñoz-Ocaña ${ }^{1}$
}

Received: 30 April 2020 / Accepted: 2 July 2021 / Published online: 9 September 2021

(c) The Author(s), under exclusive licence to Springer Nature B.V. 2021

\begin{abstract}
In this work, spatial analysis was used to identify the locations of entrepreneurs supported by the regional government of Andalusia (Spain). The objective of this research is to study the effectiveness of the support work for entrepreneurship carried out by the Andalusians Entrepreneurship Centres (CADEs) in the autonomous community. As a first approach to this objective, the geographical situation of the supported entrepreneurs is determined, and how that situation influences the support for entrepreneurship is analysed. We use spatial pattern analysis techniques that allow us to assess the impact of these efforts. Attending to the areas of greater concentration as well as those of lower concentration, we conclude that CADEs are an effective instrument of the entrepreneurship policy in this region. In addition, by concentrating on rural and mountain areas, the work of CADEs contributes to the local development of these zones by supporting the development and sustainability of the business sector in areas with higher unemployment rates and a greater threat of depopulation. The study's conclusions are relevant in showing the role of public administration in the development of European Union (EU) Objective 1 regions and, more specifically, in the support of entrepreneurship.
\end{abstract}

Keywords Entrepreneurship · Public policy $\cdot$ Supporting entrepreneurship $\cdot$ Local development $\cdot$ Spatial analysis

JEL D22 - L26 - L53

Araceli de los Ríos-Berjillos arios@uloyola.es

Extended author information available on the last page of the article 


\section{Introduction}

Entrepreneurship plays an important role in socioeconomic development. It is a key factor in reducing unemployment and in building a competitive economy. The literature has broadly addressed the relationship between local and entrepreneurship development (Anton \& Onofrei, 2016; Bienkowska, 2013; Jorge-Moreno, 2017; Katimertzopoulos \& Vlados, 2017; Skica et al., 2014). Most of the extant studies emphasize that local and regional development help expand society's potential by harnessing people's capability to initiate ideas that have economic and social impact and by making growth possible, not only in terms of employment but also in terms of economic and social development in their respective territories.

Given the direct impact of local and regional development on citizens' quality of life, the promotion of entrepreneurship has become an increasingly important policy approach for public administration. For Skica et al. (2014), the development of small and medium-sized enterprises (SMEs) is one of the main objectives of a country's economic policy. The definition of SMEs can be found in Directive 2013/34/EU (EU Parliament, 2013).

Although many studies had already dealt with entrepreneurship (Audretsch \& Beckmann, 2007; Godtfredsen, 2007), the global financial crisis of 2008 reinvigorated this line of research, and many authors and international institutions began to address the issue of entrepreneurship (Fritsch \& Storey, 2014; Fritsch \& Wyrwich, 2014; Ribeiro-Soriano \& Galindo-Martín, 2012, among others).

Supranational institutions also joined this line of research. The OECD has led support for SMEs and the promotion of entrepreneurship among its member countries, as shown by the numerous documents they have published (OECD, 2009, 2010, 2012, 2017). Other supranational institutions, such as the United Nations (2014) and the European Union (EU Commission, 2012), have followed this approach to the promotion and support of entrepreneurship. In particular, the EU Entrepreneurship 2020 Action Plan (EU Commission, 2012) identifies three aspects of immediate intervention: increasing entrepreneurial education and training to support growth and enterprise creation, eliminating existing administrative barriers and supporting entrepreneurs in crucial phases of their companies' life cycles, and reviving the culture of entrepreneurship in Europe and nurturing a new generation of entrepreneurs. The plan's motivating factor is based on the belief that for Europe to grow again and to create new jobs, entrepreneurs are needed. The role of public administration is especially relevant in rural and more isolated areas, where such services are more difficult to access.

A few works have addressed the Spanish case despite Spain being the EU country with the second highest unemployment rate $(14.1 \%)$ and the third highest unemployment rate over less than 25 years $(32.6 \%)$. In Spain, regional differences in business development and entrepreneurship are very pronounced (Ács et al., 2015).

Spain has a population of 47 million inhabitants and 8131 municipalities. Twenty-nine percent of the population lives in a rural municipality. Moreover, 
$61.5 \%$ of the municipalities have less than 1000 inhabitants. The nation's rural municipalities are very heterogeneous, but the majority of them have suffered, to a greater or lesser extent, the effects of depopulation (Recaño, 2017).

A region of special interest is Andalusia, Spain's second largest region, which occupies $17.3 \%$ of its territory and where $18 \%$ of its population lives. Despite its size and the importance of its population, Andalusia is one of the least developed regions in Spain and the EU, as indicated by the fact that it has once again become an EU Objective 1 region (Micciché, 2018).

Andalusia is located south of the Iberian Peninsula. It is the southernmost region of mainland Europe. Its geographical location is relevant since Andalusia is a bridge between Africa and Europe and a meeting point between the Atlantic and the Mediterranean. The Andalusian territory is administratively divided into eight provinces (Almería, Cádiz, Córdoba, Granada, Huelva, Jaén, Málaga and Seville) and 773 municipalities. Twenty-seven percent of these municipalities have less than 1000 inhabitants, and only $1.5 \%$ of them have more than 100,000 inhabitants. There are also great differences among the sizes of the municipalities, the largest occupying $1255 \mathrm{~km}^{2}$ and the smallest occupying $2 \mathrm{~km}^{2}$. Moreover, the Andalusian territory is very heterogeneous and includes rural and urban areas, mountainous and coastal areas, and fertile and desert areas.

The region's economic structure is characterized by a focus on the service sector, but its agrarian sector nevertheless remains the region's fundamental pillar as it contributes to cohesion and territorial equilibrium and to population and rural area development (Junta de Andalucía, 2014).

Business initiatives remain limited as evidenced by the creation of the Entrepreneurship Development Act (Junta de Andalucía, 2018). The engagement of public administration in support of these initiatives has improved greatly in recent years, and as far as we know, no studies have addressed the effectiveness of such policies in the region.

It is imperative that the role of public intervention in these initiatives be strengthened and improved; therefore, studies are needed that consider the administrative support provided to entrepreneurship projects and how such projects are transformed into regional businesses and improve the region's business network. Hence, this research analyses whether the projects and registered businesses that receive administration support show geographical relationships. Such an understanding could lead to improvements in the local economy in the territory.

To study these issues, a geographical analysis must be conducted that allows for the evaluation of the intervention of administrations in promoting business creation globally in the region as well as locally. Therefore, given the geographical and social heterogeneity of Andalusia, the analysis of the effectiveness of public entrepreneurship policies should not be analysed exclusively from the usual statistical perspective. This analysis requires taking into account the spatial divergence between study units in terms of accessibility, rurality, or population size and density. Therefore, geographic location is a key component that should not be ignored in this type of analysis (Maas et al., 2019). On this basis, this type of study should employ spatial data, i.e., data collected from a given territory and thus based on a known location (García-Alonso et al., 2014). This consideration allows for the identification of and (when necessary) action 
in areas where limitations have been detected. Moreover, such analysis would allow research on the relationship between entrepreneurship support programs and other specific variables such as socioeconomic regional indicators (Rodero-Cosano et al., 2014).

Spatial data can be analysed using various statistical spatial methods to detect spatial clusters within distributions (Shekhar et al., 2011). Spatial cluster analysis usually involves two steps: identifying spatial clusters via exploratory spatial analysis and then relating the clusters' other factors through multivariate analysis to find the original causes of the identified phenomenon (Wakefield et al., 2000).

Since Plummer (2010) focused on the application of these techniques in entrepreneurship, several studies have been conducted in this area (Audretsch et al., 2015; Bishop, 2012; Espinoza et al., 2019; Guerra \& Patuelli, 2014). Although several works, such as those indicated, have analysed entrepreneurship and its associated factors, few works have analysed public support for entrepreneurship and its associated factors.

In light of the above, the principal aim of this research is to study the effectiveness of the entrepreneurship support policies adopted in Andalusia. The following hypotheses with regard to this aim are proposed:

i. The geographical situation of the supported entrepreneurs influences the support for entrepreneurship.

ii. Entrepreneurship support policies for SMEs have grown significantly more robust in Andalusia since the financial crisis of 2008.

iii. Andalusian entrepreneurship support policies were intensified from 2006 to 2015 with a focus on providing training services to isolated areas and advisory services on how to start a business.

To confirm the stated hypotheses, we carry out analyses of the spatial and temporal patterns of support activities delivered by the government agency Andalucia Emprende from 2006 to 2015. This period covers the years before and after the last economic crisis. Two variables were used for this purpose: the first indicator was the index of supported projects (ISP) under the auspices of Andalucia Emprende in each municipality, and the second indicator was the index of registered businesses (IRB) of the total projects supported by Andalucia Emprende in each municipality.

The following section presents a bibliographical review of the role of public administration in the promotion of entrepreneurship with a focus on the Spanish case and on the region of Andalusia. Sections three and four describe the methodology and list the results. Finally, the results are discussed, and conclusions and avenues for future research are presented.

\section{Policy to Support Entrepreneurship}

Entrepreneurs create jobs, facilitate and shape innovation, and accelerate structural changes in the economy. By intensifying competition, they indirectly contribute to productivity. An entrepreneurial spirit is therefore a catalyst of economic growth, innovation and national competitiveness (Mustafa-Topxhiu, 2012). 
For Mustafa-Topxhiu (2012), a holistic approach to the promotion of entrepreneurship both nationally and locally must be supported by two basic pillars: the strengthening of entrepreneurial skills and the improvement of business environment conditions. These two pillars should be regarded as an interconnected set of policies. With regard to the conditions of the business environment, it is known that a stable macroeconomic environment, local physical infrastructure, fiscal policies, the quality of institutions, education and health influence economic activity and directly affect entrepreneurial spirit. Other policies central to business activities are those that provide ease of access to finance, administrative facilities for the entry and exit of enterprises and, more generally, policies that support SMEs.

Mustafa-Topxhiu (2012) notes that local policies are articulated around four main axes: the improvement of the competitiveness of local companies, the attractiveness of internal investments, the improvement of human capital, and the improvement of infrastructure. The main objective of such policies is to create a balanced and integrated local strategy that will incorporate economic activity into a particular territory.

For Anton and Onofrei (2016), public policies that support entrepreneurship must be based on a thorough understanding of the phenomenon of entrepreneurship and of its internal and external factors. Moreover, an evaluation of the results of previous governmental measures is a necessary condition for improving future policies. These authors emphasize the importance of the role of public administration in supporting entrepreneurship since, on the one hand, very young companies have no guarantee of success or of a trajectory for receiving financing. In addition, support for the private sector is limited as that sector has access to little information on this mode of business.

Although entrepreneurship policies serve as mechanisms that can stimulate economic growth, employment generation and competitiveness (Audretsch \& Beckmann, 2007), their effectiveness has been questioned (Arshed et al., 2014). According to Shane (2009), these policies' lack of effectiveness can be attributed to how they are implemented. In this sense, that author states that entrepreneurship policies invite people to engage in activities that are likely to fail because they attract little economic interest, have limited impact and generate little employment. From a more positive perspective, Eklund et al. (2020) state that managing failure is also a means of strengthening competitiveness and growth, making it possible to stimulate the market by reshuffling resources into new activities.

Arshed et al. (2014) address the lack of effectiveness of policies on entrepreneurship from another perspective. Their conclusions address issues related to the process of formulating business policies where the particular interests of certain actors interfere. They conclude that given the ineffectiveness of business policies created to ensure economic growth, it is important that efforts in the field of entrepreneurship support productive activities. These conclusions coincide with those of Ladeira and Machado (2013) who show that subsidies are inversely related to the capacity to generate income. They emphasize the need for more studies that address the suitability and applicability of such policies.

At the European level, there are already some works, such as Bienkowska (2013), that analyse the impact of supranational policies. In their conclusions, they note that 
EU funds have helped local authorities launch training and promotion activities for local businesses. Such subsidies are not exempt from the difficulties, such as administrative bureaucracy and the slowness of the processes involved, that hinder development. On this issue, Aparicio et al. (2016) indicate that simple and stable regulatory environments, as well as transparency, can help stimulate business creation.

\section{Andalucía: Public Instruments for Supporting Entrepreneurship}

Instruments that use entrepreneurship policies vary between countries and regions (Audretsch \& Beckmann, 2007). Cobo-Soler et al. (2018) recently conducted an analysis of agents and public instruments that support entrepreneurship in the Spanish case. For those authors, there is a traditional understanding that reduces the support of public administration for the undertaking of grant financial aid by ministries. However, in addition to having access to subsidies, entrepreneurs can access other diverse initiatives and seek support from different levels of public administration including at the central, regional and local levels. Depending on the stage currently occupied by a project, one form of assistance can be more useful than another. Table 1 lists the set of initiatives designed to support entrepreneurship in accordance with their monetary or nonfinancial features. These initiatives must be combined with those at the EU level. Monetary aid is not incompatible with monetary funds; in fact, they complement one another.

Credit restriction was one of the main impacts of the global financial crisis that began in 2008. Many governments started new programmes to encourage the financing of SMEs such as government-subsidized credit lines, public guarantee funds, venture capital funds and other public schemes of support for SMEs (Anton \& Onofrei, 2016).

Non-monetary aid is increasingly important. Through mentoring, entrepreneurs receive support and advice from different specialists and professionals in different phases of business development. Such support is of particular importance when starting a project (Cobo-Soler et al., 2018).

Table 1 Typology of entrepreneurial support mechanisms

\begin{tabular}{ll}
\hline Monetary & Loans \\
& Participative loans \\
& Subsidies, venture capital \\
& Tax incentives \\
& Financial and technical guarantees \\
Mentoring & Co-working \\
Trial tests & Networking \\
One-stop source \\
Identification of needs and opportunities \\
Incubation and acceleration \\
Awards \\
\hline
\end{tabular}

Source Cobo-Soler et al. (2018) 
The literature has recently dealt with the benefits of mentoring in supporting entrepreneurship. Benefits include the mentor sharing his or her knowledge, skills and experience and helping anticipate harmful situations. Mentors can also provide psychological support, helping entrepreneurs face their fears and concerns and improve their levels of motivation (Mckevitt \& Marshall, 2015; Wilbanks, 2015). The authors state that it is the mentor's obligation to remain abreast of the latest trends in a changing environment to avoid promoting obsolete practices. In addition, support must be sustained over time rather than only at the beginning of the process or only occasionally.

Advice is usually given through companies' incubators or accelerators, which are physical spaces for work that an administration makes available to entrepreneurs. Aernoudt (2004) warns that while incubation is increasingly being used as a tool to promote entrepreneurship and enterprise creation, leading to new political incentives, it is necessary to assess these incubators' impacts based on their typology. This author also emphasizes the importance of using this instrument to support entrepreneurship through business angel networks. In their work on the effectiveness of public policies in supporting entrepreneurship, Rodríguez and Tarazona (2015) recommend limiting periods of initiative incubation to prevent entrepreneurs from losing their motivation.

In Andalusia, the public organization responsible for promoting entrepreneurship and business development is called Andalucía Emprende, a public foundation affiliated with the Andalusian government. The organization's objectives are to contribute to make the regional economy more dynamic, to create companies that generate employment and to offer quality services. The CADEs support the projects of entrepreneurs who come to them for assistance, some of whom become registered businesses with this support and others who do not. For this reason, for references to CADEs activities that are made herein, supported projects should be distinguished from those that become registered businesses.

Andalucía Emprende employs a centralized approach, addressing 37 areas of action to cover the entire region and managing eight provincial directorates located in Andalusian capitals including 61 information centres and 250 Andalusian Centres of Entrepreneurship (CADEs).

Entrepreneurs can go to these centres to obtain assistance in business development or to obtain business accommodations or training, training for employment, tutoring, advice and follow-up guidance on business plans and financial advice. Companies already in operation can obtain assistance with corporate consolidation and strategic decision-making. CADEs therefore offer mentoring, training and incubation services.

Since Andalucía Emprende's creation, the CADEs have enhanced their support for entrepreneurship, as shown in Table 2. In 2008, coinciding with the beginning of the economic crisis, a growing and accelerating trend of support for entrepreneurship from this organization was observed.

From the above data, studying the effects of entrepreneurial policies developed in the region is essential to enhancing their efficiency. 
Table 2 Number of entrepreneurs supported by the CADEs

\begin{tabular}{lrrrrrrrrrrrrr}
\hline & 2004 & 2005 & 2006 & 2007 & 2008 & 2009 & 2010 & 2011 & 2012 & 2013 & 2014 & 2015 & Total \\
\hline Almería & 1 & 17 & 171 & 81 & 43 & 103 & 260 & 200 & 227 & 265 & 234 & 237 & 1839 \\
Cádiz & 5 & 31 & 218 & 231 & 79 & 171 & 354 & 159 & 140 & 179 & 141 & 199 & 1907 \\
Córdoba & 6 & 14 & 122 & 77 & 61 & 112 & 268 & 226 & 393 & 667 & 544 & 573 & 3063 \\
Granada & 2 & 11 & 254 & 131 & 83 & 126 & 296 & 201 & 291 & 247 & 224 & 227 & 2093 \\
Huelva & 1 & 18 & 172 & 124 & 71 & 152 & 260 & 207 & 216 & 200 & 196 & 180 & 1797 \\
Jaén & 1 & 17 & 110 & 98 & 64 & 161 & 72 & 137 & 280 & 193 & 149 & 206 & 1488 \\
Málaga & 2 & 16 & 228 & 189 & 106 & 426 & 731 & 570 & 777 & 931 & 758 & 924 & 5658 \\
Sevilla & 8 & 25 & 289 & 184 & 139 & 351 & 1041 & 685 & 935 & 1101 & 970 & 1123 & 6851 \\
Total & 26 & 149 & 1564 & 1115 & 646 & 1602 & 3282 & 2385 & 3259 & 3783 & 3216 & 3669 & 24,696 \\
\hline
\end{tabular}

Source CADEs, Junta de Andalucía

\section{Empirical Study}

\section{Study Scope}

We focus on the Andalusian region because it is important to generate knowledge on areas in which the level of need is the greatest. This autonomous community presents the lowest economic indicator scores, as shown in the following table (Table 3).

Within the Andalusia Autonomous Region, regarding rates of business per labour force, patterns observed in each province vary considerably (Table 4), with Málaga being the only province to present values exceeding the national average. Values of this indicator illustrate the need to promote entrepreneurship for improvement and to achieve the national rate.

\section{Studied Variables}

To study the hypotheses advanced regarding the support activities provided by 250 Andalusian Enterprise Centres in the studied territories, as our analysis unit, we studied 773 Andalusian municipalities and analysed three indicators. To this end, the government agency Andalusia Emprende provided us with its annual data

base at the municipal level of the supported projects and the supported projects that were finally registered businesses from 2006 to 2015 . All data provided by this agency were automatically anonymized by the system and contain no personal data. The study analysed the information at the municipality level and did not show any data at an individual level in compliance with all the established ethical standards.

The indicators used in the study are from the above-described raw database and are calculated following the process indicated below.

The first indicator was the supported projects that became registered businesses. For this, the studied variable is the registered business index (IRB), which is 
Table 3 Ranking of the Spanish regions compared to national average

\begin{tabular}{llllll}
\hline Ranking & & & \multicolumn{2}{l}{ Ranking } \\
GDP per capita & & Uanking & & Business per labour force rate \\
\hline Madrid, Comunidad de & 1.352 & Balears, Illes & 0.492 & Cataluña & 1.115 \\
País Vasco & 1.324 & Cantabria & 0.618 & Galicia & 1.100 \\
Navarra & 1.237 & País Vasco & 0.647 & Madrid & 1.087 \\
Cataluña & 1.197 & Rioja, La & 0.660 & Asturias & 1.032 \\
Aragón & 1.096 & Navarra & 0.663 & Rioja, La & 1.023 \\
Rioja, La & 1.042 & Aragón & 0.678 & Comunitat Valenciana & 1.004 \\
Balears, Illes & 1.031 & Cataluña & 0.731 & Spain & 1 \\
Spain & 1 & Castilla y León & 0.777 & Balears, Illes & 0.988 \\
Castilla y León & 0.942 & Madrid, Comunidad de & 0.815 & Castilla y León & 0.987 \\
Cantabria & 0.901 & Galicia & 0.841 & Aragón & 0.973 \\
Galicia & 0.900 & Asturias, Principado de & 0.924 & Cantabria & 0.973 \\
Comunitat Valenciana & 0.882 & Spain & 1 & País Vasco & 0.972 \\
Asturias, Principado de & 0.882 & Comunitat Valenciana & 1.051 & Navarra & 0.965 \\
Murcia, Región de & 0.823 & Murcia, Región de & 1.122 & Extremadura & 0.923 \\
Canarias & 0.817 & Castilla-La Mancha & 1.148 & Murcia, Región de & 0.920 \\
Castilla - La Mancha & 0.787 & Canarias & 1.350 & Castilla - La Mancha & 0.890 \\
Ceuta & 0.781 & Extremadura & 1.490 & Andalucía & 0.887 \\
Andalucía & 0.739 & Andalucía & 1.570 & Canarias & 0.884 \\
Melilla & 0.718 & Melilla & 1.650 & Melilla & 0.791 \\
Extremadura & 0.691 & Ceuta & 2.116 & Ceuta & 0.691 \\
\hline
\end{tabular}

Source National Statistical Institute (INE)

Table 4 Ranking of the Andalusian province businesses per labour force rate

\begin{tabular}{|c|c|c|c|c|}
\hline & $\begin{array}{l}\text { Business/labour } \\
\text { force }^{\mathrm{a}}\end{array}$ & Ranking by regions & $\begin{array}{l}\text { Index above the } \\
\text { national average }\end{array}$ & $\begin{array}{l}\text { Index above } \\
\text { the regional } \\
\text { average }^{c}\end{array}$ \\
\hline Spain & 0.146 & Málaga & 1.076 & 1.213 \\
\hline Andalucía & 0.130 & Spain $^{d}$ & 1 & 1.084 \\
\hline Almería & 0.128 & Granada & 0.922 & 1.040 \\
\hline Cádiz & 0.108 & Córdoba & 0.890 & 1.003 \\
\hline Córdoba & 0.130 & Andalusia $^{d}$ & 0.997 & 1 \\
\hline Granada & 0.135 & Almería & 0.874 & 0.986 \\
\hline Huelva & 0.103 & Sevilla & 0.862 & 0.972 \\
\hline Jaén & 0.123 & Jaén & 0.844 & 0.952 \\
\hline Málaga & 0.157 & Cádiz & 0.741 & 0.835 \\
\hline Sevilla & 0.126 & Huelva & 0.706 & 0.797 \\
\hline
\end{tabular}

Source National Statistical Institute (INE)

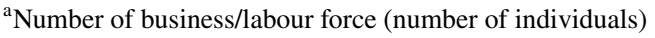

${ }^{\mathrm{b}}$ Business/labour force province/Business/labour force Spain

${ }^{\mathrm{c} B u s i n e s s / l a b o u r}$ force province/Business/labour force Andalucía

${ }^{\mathrm{d}}$ Country and Region of study Data 
calculated as the registered businesses weighted for the labour force of each municipality (INE, 2015) in thousands of people per year from 2006 to 2015.

$$
I R B=\frac{1}{n} \sum_{1}^{n} \frac{R B_{i}}{L F_{i}} 1000
$$

$R B_{i}$ denotes the total number of businesses with support registered in year $i, L F_{i}$ denotes the labour force in year $i$, and $n$ is the number of years running from 2006 to 2015.

Moreover, we studied businesses registered in each period to analyse the effects of the financial crisis on the support activities of the Andalusian Enterprise Centre. To this end, we calculated the indexes for the following periods: 2006-2007, 2008-2010, 2011-2013, and 2014-2015.

The second indicator was the supported projects index (ISP), calculated as the number of all support projects weighted to the labour force in each municipality (INE, 2015) in thousands of people for 2006-2015.

$$
I S P=\frac{1}{n} \sum_{1}^{n} \frac{S P_{i}}{L F_{i}} 1000
$$

$S P_{i}$ denotes the number of projects supported in year $i, L F_{i}$ denotes the labour force in year $i$, and $n$ denotes the number of years running from 2006 to 2015.

Finally, the third indicator was the rurality index proposed by Goerlich et al. (2016). This indicator proposes a rural/urban typology at the municipal level for Spain taking into account three criteria: the demography, which combines densities with minimum population thresholds; information on land cover and land use and the degree of accessibility from the rural world to cities. As a result, the third indicator establishes six different types of municipalities based on their level of rurality.

\section{Methodology}

Geographic localization is a fundamental component of analyses of regional indicators such as entrepreneurship. According to the Law of Tobler (1970), "everything is related to everything else, but the close things are more related than things far away", and thus disregarding this component could be misleading. Spatial data are characterized by a location in space that allows one to examine the spatial relations between different points. These data are analysed using specific techniques of spatial data analysis that are employed when it is considered important to measure the localization and potential spatial relations of the variables for the interpretation of a given phenomenon. Spatial data analysis can be defined as the quantitative study of phenomena observed in space and as the measurement of the spatial dependence of observations (Bailey \& Gatrell, 1995). It is a statistical methodology that takes into account the spatial relationships (adjacency, contiguity, proximity, etc.) between the areas where a phenomenon takes place. Spatial analysis measures the strength of the observed spatial dependence. In recent years, the development of geographic information systems has facilitated and promoted the use of geostatistical methods. 
Such spatial relationships are formally expressed in a matrix of spatial weights $\mathrm{W}_{i j}$, where the notation $i, j$ corresponds to each pair of observations. That is, for a set of spatial data made up of $n$ locations, the spatial weighting matrix expresses the potential for interaction between observations at each pair $i, j$ of locations (Chasco, 2013). In this research, spatial relationships between the units of analysis (municipalities) were defined by a matrix of spatial weights $\left(\mathrm{W}_{i j}\right)$ that was calculated according to the queen contiguity-based rule of the first order (Cliff $\&$ Ord, 1969). This approach defines neighbouring units as those with a common point or border. This contiguity rule was selected due to the high variability in the size of the spatial units to ensure a similar number of neighbours for each unit.

One of the most widely used spatial analysis approaches involves examining spatial patterns in the distribution of data in geographic space (Shekhar et al., 2011). This technique is used to determine whether there are spatial clusters of similar or dissimilar values of one or more variables, spatial autocorrelations or multivariate spatial correlations (Salinas Pérez, 2012).

To accomplish this goal, the spatial dependence of variables due to their localization and distribution in geographic space is measured. Spatial concentrations of similar values, usually those that are significantly high or low, indicate the presence of positive spatial dependence (concentration) while clusters of different values denote negative spatial dependence (dispersion).

Analyses used to study clusters or significant concentrations of phenomena in space vary considerably (Auchincloss et al., 2012), and one of the most wellknown is spatial autocorrelation. This analysis involves measuring the presence of spatial dependence at the univariate level and is classified into global and local approaches. Global methods analyse a whole study area to determine whether there is spatial dependence in the set of observations and thus if a spatial structure is determined by the location of data, but this approach does not allow for the detection of specific clusters. As a complement, local methods reveal the specifics of spatial clusters. In spatial analysis studies, both types are typically used because a general analysis of the former can conceal patterns occurring in small clusters that can be detected through the second analysis. For this reason, global and local methods sometimes generate different results for the same distribution (Salinas Pérez, 2012). In this study, we used the Moran I statistic (Moran, 1950) for global spatial autocorrelation.

$$
I=\frac{n}{\sum_{i=1}^{n} \sum_{j=1}^{n} w_{i j}} \frac{\sum_{i=1}^{n} \sum_{j=1}^{n} w_{i j}\left(x_{i}-\bar{X}\right)\left(x_{j}-\bar{X}\right)}{\sum_{i=1}^{n}\left(x_{i}-\bar{X}\right)^{2}}
$$

$x_{i}$ is value $\mathrm{x}$ of localization $i$; $\bar{x}$ is the average of value $x ; x_{j}$ is value $\mathrm{x}$ for any localization except for $i(j \neq i) ; w_{i j}$ is the spatial peer-to-peer weight matrix; $n$ is the total number of spatial units.

More recently, local methods have been developed called local indicators of spatial association (LISAs), and they are used here in employing statistical local G* (Getis \& Ord, 1992). 


$$
G_{i}^{*}=\frac{\sum_{j=1}^{n} w_{i j} x_{j}-\frac{\sum_{j=1}^{n} x_{j}}{n} \sum_{j=1}^{n} w_{i j}}{\sqrt{\frac{\sum_{j=1}^{n} x_{j}^{2}}{n}-\left(\frac{\sum_{j=1}^{n} x_{j}}{n}\right)^{2}} \sqrt{\frac{\left[n \sum_{j=1}^{n} w_{i j}^{2}-\left(\sum_{j=1}^{n} w_{i j}\right)^{2}\right]}{n-1}}}
$$

$x_{j}$ is value $\mathrm{x}$ of localization $j ; w_{i j}$ denotes the peer-to-peer spatially weighted matrix; $n$ is the total number of spatial units.

To interpret global and local indicators, we calculated their standard values ( $z$-values). $Z$-values allow one to calculate the probability $(p)$ of the null hypothesis $\left(H_{0}\right)$, indicating an absence of spatial patterns and a random spatial distribution. The values of these indicators with a probability below $0.05(z \geq 1.960$ and $z \leq--1.960)$ are significant as this denotes a $5 \%$ chance of $H_{0}$ being met and thus of the distribution being random. The municipalities identified as hot/cold spots were statistically compared to the others using two nonparametric methods designed for independent samples: Mann-Whitney's $U$ test and the comparison of medians (Mann \& Whitney, 1947).

Once spatial dependence is confirmed, it is necessary to check that the predictor variables show spatial trends similar or dissimilar to the target variable. To this end, we conducted a spatial bivariate Moran scatter plot analysis (Anselin et al., 2006). This type of analysis measures the degree to which the value for a given variable at a location is correlated with its neighbours for a different variable.

$$
I_{B}=\frac{\sum_{i=1}^{n}\left(\sum_{j=1}^{n} w_{i j} \mathrm{y}_{j} x_{i}\right)}{\sum_{i=1}^{n} x_{i}^{2}}
$$

$x_{i}$ is value $x$ of localization $i ; y_{j}$ i value $y$ for any localization except for $i(j \neq i)$; $w_{i j}$ is the spatial peer-to-peer weight matrix; $n$ is the total number of spatial units. All variables are expressed in standardized form, and the spatial weights are row-standardized.

Given our research aims to analyse spatial effects across municipalities and relationships with associated factors, we conducted ordinal least squares and spatial regressions. Our analysis assumes that errors meet the following requirements: a normal distribution with a mean of zero exhibiting homoscedasticity and independence (Greene, 2018). However, when variables present spatial correlations, such assumptions cannot be made, and research should resort to the use of other techniques (Anselin, 2001).

There are two ways to introduce spatial dependence: as an additional regressor with a spatial lag dependent variable or from the structure of the error. Since the spatial lag model is appropriate to use when evaluating the strength of spatial interactions (Anselin, 2001), we adopted this approach.

Formally, the spatial lag model or spatial autoregressive model is expressed as follows:

$$
y=\rho W_{y}+\beta x+\varepsilon
$$

$\rho$ is a spatial autoregressive coefficient, $w$ is the spatial lag dependent variable, $\beta$ is the regression coefficient, $x$ is the independent variables and $\varepsilon$ is a vector of error 
terms. In this model, $W_{y}$ correlates with disturbances. Consequently, the term spatial lag should be treated as an endogenous variable, and the maximum likelihood method is adopted as the appropriate estimation approach.

When there are high levels of heterogeneity in a spatial distribution, it is advisable to use geographically weighted regression (Fotheringham, 2002) to assess for which areas the predictive variables better predict the values of entrepreneurship support. This regression approach generates a local model of the variable predicted by adjusting a regression equation to each characteristic of the dataset, and each local regression is estimated with data whose effect decreases with Euclidean distance. A bandwidth based on the Akaike information criterion (AIC) method identifies the optimal distance based on the geographical distribution of the features. This model is very useful when local variations do not allow for the adjustment of the global model (Brunsdon et al., 1996).

The analysis was carried out using the GeoDA 1.8 program (Anselin et al., 2006) and ArcGIS Pro (Version 2.5) (Esri Inc., 2020).

\section{Results}

\section{Spatial Dependence}

The first step involved the calculation of the variable project-supported index and business registered index (Fig. 1). We created maps of distributions of the variables for the municipalities of Andalusia and standard deviations in the distribution of each variable, revealing very high (red) and low (blue) values of the indicator. The project-supported index mean is 2.26 per 1,000 labourers $( \pm 0.09 ; p=0.05)$ with a standard deviation of 1.29 , and the business registered index mean is 0.55 per 1,000 labourers $( \pm 0.04 ; p=0.05)$ with a standard deviation of 0.55 , showing that registered business indexes vary widely across different municipalities. These differences are not randomly distributed across the territory as otherwise positive and

Fig. 1 Location of Andalusia in Spain and Europe. Source: Own elaboration based on map of European Union (https://europa. eu/european-union/about-eu/ countries_en)

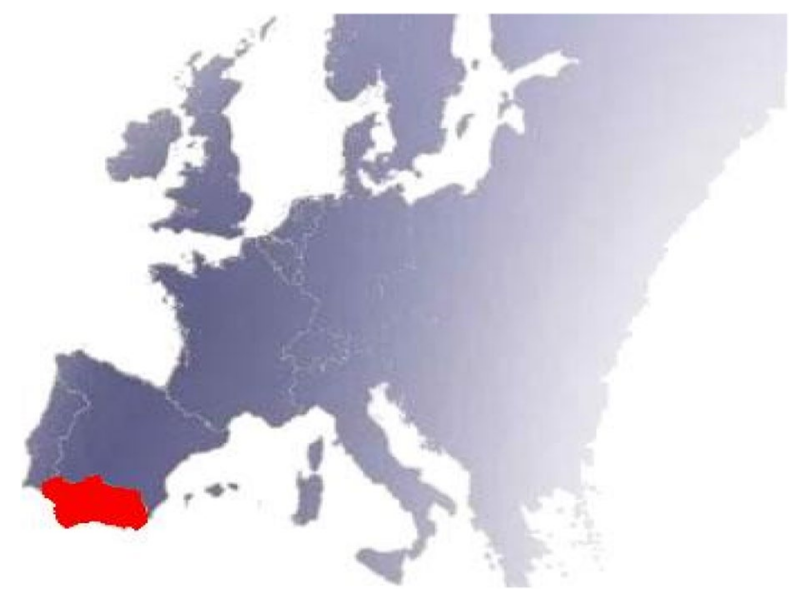


statistically significant spatial correlations according to global Moran's $I$ ( $I_{I S P}=0.23$, $\left.z=10.64, p \leq 0.00 ; I_{I R B}=0.25, z=11.62, p \leq 0.00\right)$ would be present. Thus, business support is affected by what occurs in neighbouring municipalities as a common consequence of the creation of companies is the creation of related companies.

The results show that the eastern regions of Sierra Morena and Sierra Subbetica present higher index values while values are particularly marked in certain northern rural municipalities. However, in the western areas of Cadiz and Huelva and in the central Guadalquivir Valley, support is less marked.

Once spatial autocorrelations of the variables were confirmed, a local analysis was applied to detect patterns and to visualize clusters of significantly high and low values. Maps of distributions of both indexes and of their significance, as indicated in green, are shown in Fig. 2.

To confirm the presence of these patterns, U Mann-Whitney and median tests for independent samples were applied to the values of both indicators. The goal was to compare distributions and medians of levels of entrepreneurship support across municipalities situated in hot or cold spots relative to other studied municipalities to demonstrate that both groups can be considered significantly different. In both cases, we find that these municipalities present significantly higher values than the
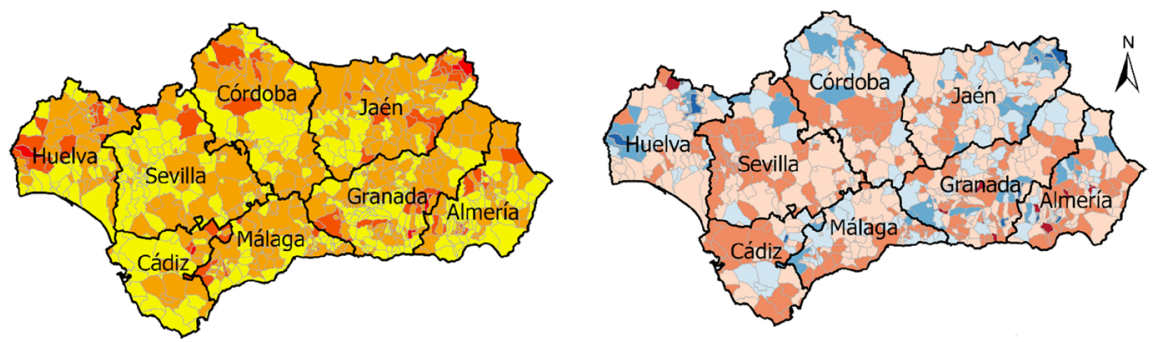

(a)
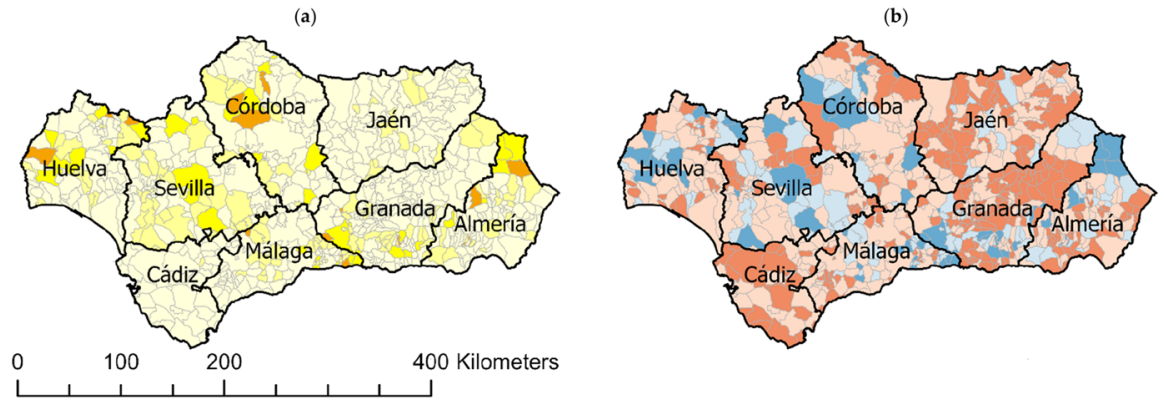

(c)

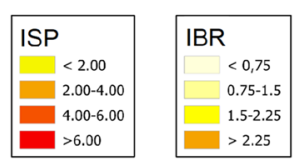

(d)

Fig. 2 Support Activity of CADE. a Supported Projects Index-ISP, b ISP standard deviation, c Registered Business Index-IRB, d IRB standard deviation 
others $\left(z_{I S P}=-8.70 * * * ; z_{I R B}=-10.70 * * *\right)$ and that significantly lower values also confirm our hypothesis $\left(z_{I S P}=-7.09 * * * ; z_{I R B}=-7.49 * * *\right)$.

From this visualization, we observe collections of low levels of project supported with respect to the labour force (blue cluster) for the capital city of Cordoba, along the corridor between the capitals of Seville and Cadiz and in areas surrounding the capitals of Granada and Almeria. This pattern may indicate that in these capital zones, due to the presence of established business networks, entrepreneurs do not seek assistance for the creation of companies. Regarding distributions of support for registered businesses, low-value clusters are concentrated in the northern area of Jaen and along the province's borders with Granada and Almeria. In these areas, established businesses receive less support relative to the labour force. Thus, for these areas, it will be necessary to review support policies as it may not be possible to effectively reach entrepreneurs. Areas showing high levels of support per the labour force (red clusters) for both indicators maintain similar patterns. These clusters are situated around mountainous areas with small labour forces where support for entrepreneurship is greatly encouraged by decision makers. In addition, the support provided in these areas is effective because registered projects are stronger in these areas than in the rest of Andalusia. Finally, we observe a third pattern whereby the business support provided to the labour force remains at average values with respect to the rest of the region (grey areas).

\section{Spatiotemporal Evolution of Enterprise Support}

To assess our second hypothesis regarding the increase in CADE support provided after the 2008 economic crisis, we carried out an evaluation of the business registered indicator for 2006 to 2015. It is important to consider that this is a spatially affected variable, as shown by the values of the global Moran index given in Table 5.

A review of the mean values shows that support activity is effectively enhanced over the course of the crisis and in the recovery period. A comparative test of the nonparametrically related samples (Table 6) confirms the hypothesis as the average value increases significantly from the start of the crisis to 2013, and thereafter, the increase is no longer significant.

To analyse the evolution of support activity, the spatial autocorrelation values of the indicators were studied locally (Fig. 3). From this analysis, it can be deduced that while CADE activity levels intensified throughout the crisis period, they were

Table 5 Spatiotemporal analysis of business registered

\begin{tabular}{lllll}
\hline Period & Mean & $\begin{array}{l}\text { Standard } \\
\text { deviation }\end{array}$ & Wilcoxon Test & $I$ Moran \\
\hline $2006-2007$ & 0.39 & 0.66 & - & $0.11^{* *}$ \\
$2008-2010$ & 0.41 & 0.53 & $-2.60 * * *$ & $0.11^{* *}$ \\
$2011-2013$ & 0.66 & 0.90 & $-8.12^{* * *}$ & $0.19^{* * *}$ \\
$2014-2015$ & 0.75 & 1.18 & -0.62 & $0.27 * * *$ \\
\hline
\end{tabular}

Source Own elaboration

${ }^{*} p \leq 0.1 ; * * p \leq 0.05 ; * * * p \leq 0.01$ 
always concentrated in mountainous rural areas such as the Sierra Nevada region where Granada is located and the Sierra Norte region where Huelva and Cordoba are located. Moreover, the analysis reveals differences in clusters of low values that become more pronounced, especially in the northern area of Jaen, along the border between this province and Granada and along the coast of Cadiz.

It should be noted that the analysed support is not financial support. Mentoring is, therefore, an appropriate administrative support instrument in a context of crisis when there are restrictions on public spending.

\section{Relationships Between Enterprise Support and Rurality}

A spatial bivariate correlation analysis of registered businesses, supported projects and rurality confirms our hypothesis of the influence of these predictor variables on the dependent variable with the following bivariate Moran's I results: $\left(I_{I R B-I S P}=0.05\right.$, $\left.z=3.32, p \leq 0.00 ; I_{I R B-R U R}=0.09, z=5.55, p \leq 0.00\right)$. These results validate our hypothesis that CADE support facilitates business creation, especially in rural areas where access to consulting services remains limited.

The results of the ordinary least squares (OLS) regression are shown in Table 6. They confirm the presence of spatial associations between the explanatory variables. The OLS regression model built with the variables supported projects and rurality did not show collinearity, although its errors were not normally distributed and the model had heterocedaticity problems. According to the diagnostic tests, the residuals presented spatial autocorrelation, which was recommended using a spatial regression. The robust LM tests showed no preference regarding what spatial regression was more suitable. However, we obtained consistent results using a spatial lag regression model.

In comparison with the OLS model, the spatial lag regression model improved in terms of adjustment and prediction. Thus, the $\mathrm{R}^{2}$ increased to 0.38 while the Akaike info criterion decreased with respect to the OLS model, and all independent variables were statistically significant. However, the tests of spatial dependence and heteroscedasticity still detected adjustment problems. This result could be attributable to the heterogeneity of the distribution, which may hide spatial regimes in the distribution. We also found that the strong relationship between supported projects and registered companies obscures the relationship between the dependent variable and rurality.

To more deeply analyse the heterogeneity of the distribution and the relationships between registered companies, a geographically weighted regression is carried out, this time only on the variable of rurality. The results of this regression are slightly worse than those of lag spatial regression, as shown by the increase in AIC, but this allowed us to more clearly determine how rurality relates to support for CADE entrepreneurship.

Table 6 shows that the relationship with rurality is weak; nevertheless, Fig. 4 shows that the detected ratio is stronger for the capital cities of Cordoba and Huelva and for the coastal area of Almeria, where $R^{2}$ values are higher. However, we find weaker ratios for the corridor between Seville and Cadiz and the 
Table 6 Dependence analysis between IBR and rurality

\begin{tabular}{|c|c|c|c|}
\hline \multicolumn{4}{|l|}{ Ordinary least square } \\
\hline & Coefficients & Standard error & $t$ \\
\hline \multicolumn{4}{|l|}{ Independent variables } \\
\hline Constant & $0.16^{* *}$ & 0.07 & 2.16 \\
\hline ISP & $0.22 * * *$ & 0.01 & 15.92 \\
\hline Rurality & -0.02 & 0.01 & -1.40 \\
\hline \multicolumn{4}{|l|}{ Regression diagnosis } \\
\hline$R^{2}$ & 0.25 & Adjusted $R^{2}$ & 0.25 \\
\hline S.E. regression & 0.55 & $F$ & $128.78^{* * *}$ \\
\hline $\mathrm{AICc}$ & $1,041.73$ & Log Likelihood & -517.89 \\
\hline \multicolumn{4}{|l|}{ Multicollinearity diagnosis } \\
\hline Condition number & 9.69 & & \\
\hline \multicolumn{4}{|l|}{ Normality errors diagnosis } \\
\hline Jarque-Bera test & $427.94 * * *$ & & \\
\hline \multicolumn{4}{|l|}{ Heterocedaticity diagnosis } \\
\hline Breusch-Pagan test & $356.89 * * *$ & & \\
\hline \multicolumn{4}{|l|}{ Spatial dependence diagnosis } \\
\hline Moran’s I (error) & $0.33 * * *$ & & \\
\hline Lagrange multiplier (lag) & $149.66^{* * *}$ & Robust LM (lag) & $10.60 * * *$ \\
\hline Lagrange multiplier (error) & $224.36 * * *$ & Robust LM (error) & $85.29 * * *$ \\
\hline
\end{tabular}

\begin{tabular}{llll}
\hline Coefficients & Standard error & $t$ \\
\hline
\end{tabular}

Independent variables

$\begin{array}{llll}\text { Constant } & -0.06 & 0.06 & -0.04 \\ \text { ISP } & 0.21 * * * & 0.07 & 16.46 \\ \text { Rurality } & -0.04 * * & 0.01 & -2.97 \\ \text { W_BSI } & 0.48^{* * *} & 0.04 & 12.15\end{array}$

Regression diagnosis

$\begin{array}{llll}\text { Pseudo- } R^{2} & 0.38 & \text { AICc } & 922.785 \\ \text { S.E. regression } & 0.42 & \text { Log Likelihood } & -457.39\end{array}$

Heterocedaticity diagnosis

Breusch-Pagan test 449.20***

Spatial dependence diagnosis

\begin{tabular}{|c|c|c|c|c|c|c|}
\hline Likelihood ratio test & \multicolumn{2}{|c|}{$121.00 * * *$} & & & \multicolumn{2}{|c|}{$0,05 * *$} \\
\hline \multicolumn{7}{|c|}{ Geographical weighted regression (GWR) } \\
\hline & \multicolumn{3}{|c|}{ Coefficients } & \multicolumn{3}{|c|}{ Standard error } \\
\hline & Min & $\operatorname{Max}$ & Mean & Min & $\operatorname{Max}$ & Mean \\
\hline \multicolumn{7}{|l|}{ Independent variables } \\
\hline Intercept & -0.76 & 3.88 & 0.49 & 0.16 & 0.93 & 0.29 \\
\hline Rurality & -0.55 & 0.33 & 0.01 & 0.03 & 0.16 & 0.06 \\
\hline Local $R^{2}$ & 0.00 & 0.27 & 0.02 & - & - & - \\
\hline
\end{tabular}


Table 6 (continued)

Geographical weighted regression (GWR)

\begin{tabular}{|c|c|c|c|c|c|c|c|c|}
\hline & \multicolumn{4}{|c|}{ Coefficients } & \multicolumn{4}{|c|}{ Standard error } \\
\hline & Min & $\operatorname{Max}$ & & Mean & Min & & $\operatorname{Max}$ & Mean \\
\hline Local standard error & - & - & & - & 0.36 & & 0.51 & 0.49 \\
\hline \multicolumn{9}{|l|}{ Regression diagnosis } \\
\hline$R^{2}$ & 0.19 & & Adjusted $R^{2}$ & & & 0.13 & & \\
\hline Residual sum of squares & 187.24 & & Bandwidth & & & $38,427.68$ & & \\
\hline AIC & 1180.66 & & Moran's I (residuals) & & & $0.057 * * *$ & & \\
\hline
\end{tabular}

Source Own elaboration

$* p \leq 0.1 ; * * p \leq 0.05 ; * * * p \leq 0.01$

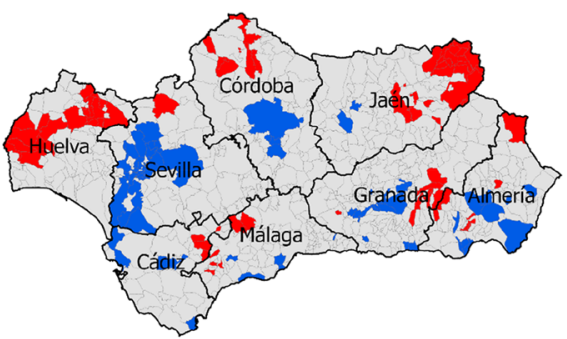

(a)

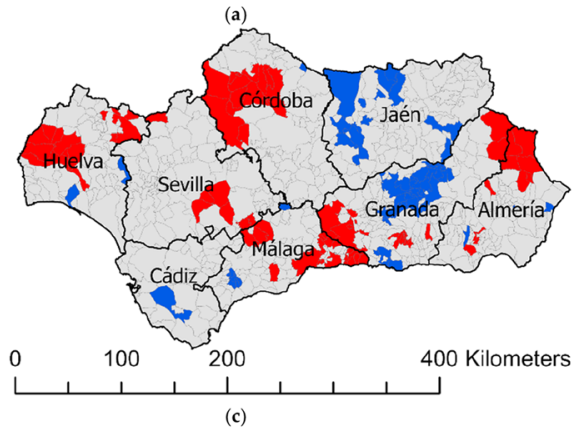

(c)

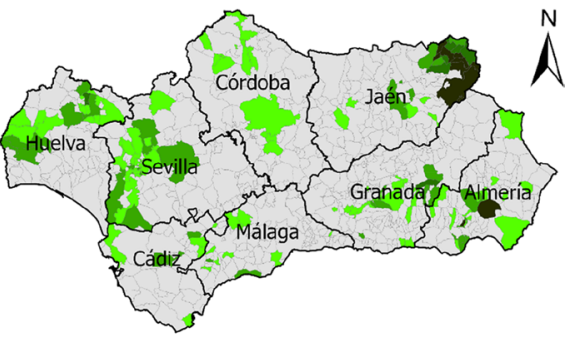

(b)

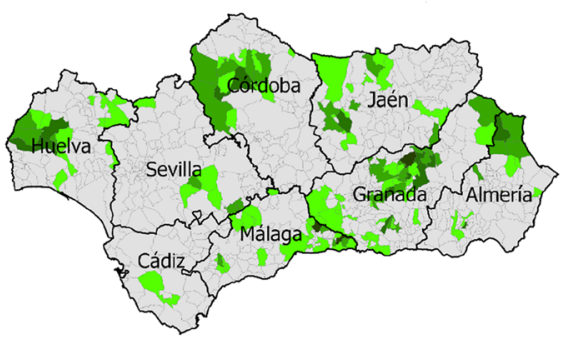

(d)

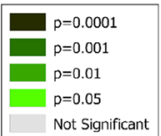

Fig. 3 Local spatial autocorrelation index $G^{*}$ and its significance. a G* ISP, b G* ISP significance, $\mathbf{c} \mathrm{G}^{*}$ IRB, d G* IRB significance

Guadalquivir Valley. For the rural areas of the northern highlands of Andalusia and for the coastal areas of Huelva and Malaga, we observe similarly high values of rurality and entrepreneurship support (Fig. 5). 

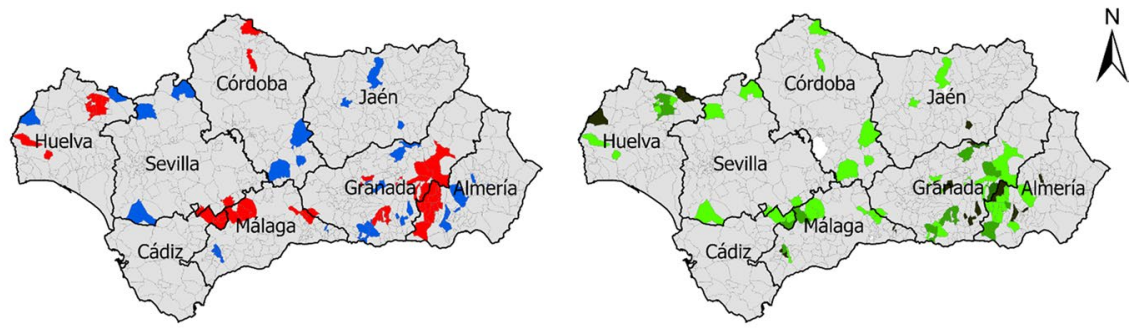

(a)

(b)
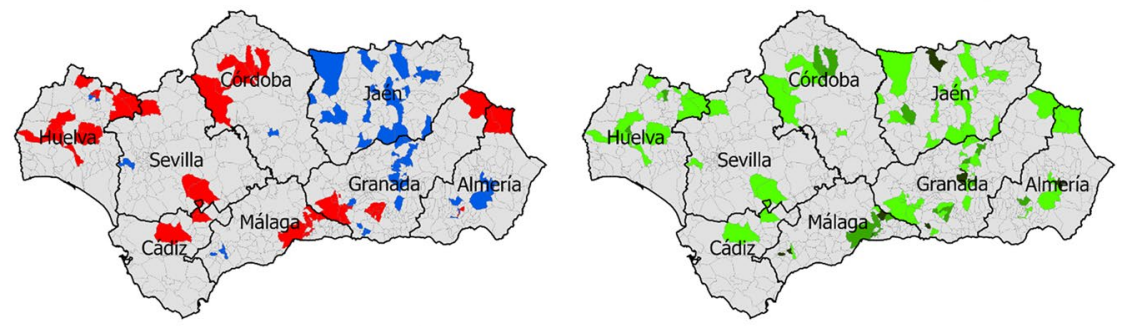

(c)

(d)
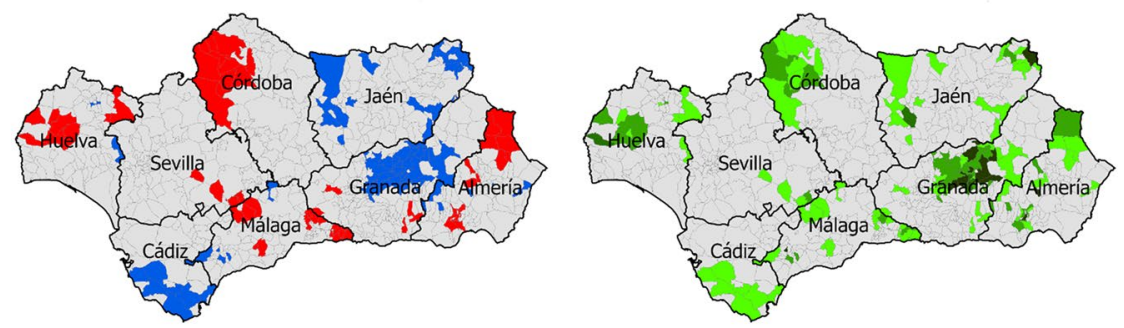

(e)
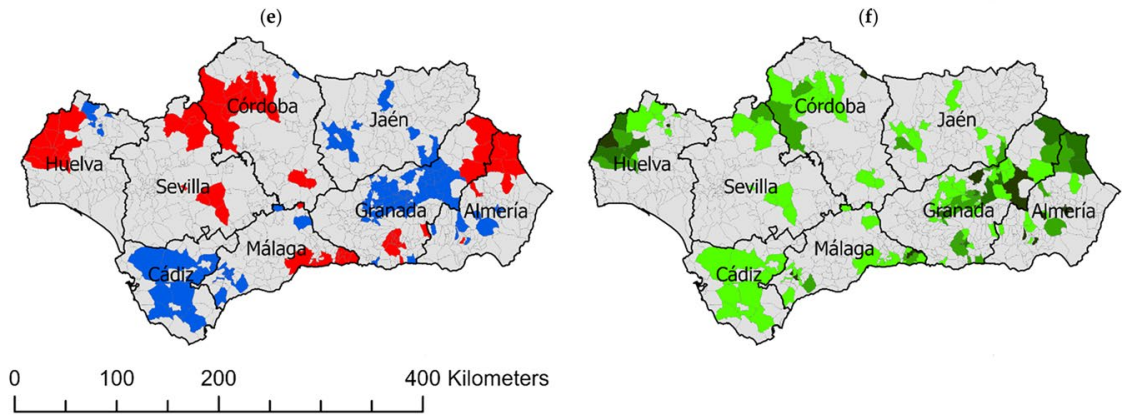

(g)

(h)
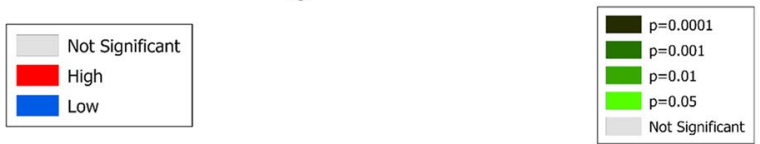

Fig. 4 Spatio-temporal evolution of enterprise support. Local spatial autocorrelation index $G^{*}$ and its significance. a $G^{*} I R B$ 2006-2007, b $G^{*} I R B$ significance 2006-2007, c $G^{*} I B R$ 2008-2010, d $G^{*} I R B$ significance 2008-2010, e $G^{*} I R B$ 2011-2013, f $G^{*} I R B$ significance 2011-2013, g $G^{*}$ IRB 2014-2015, h $G^{*} I R B$ significance 2014-2015 


\section{Discussion}

The present study examined the effectiveness of entrepreneurship support policies adopted in Andalusia based on three hypotheses. First, the entrepreneurship support efforts of the regional government are related to the geographical location. Second, entrepreneurship support efforts for SMEs have significantly intensified in Andalusia since the financial crisis of 2008. Third, Andalusian entrepreneurship support efforts intensified support from 2006 to 2015 with a focus on
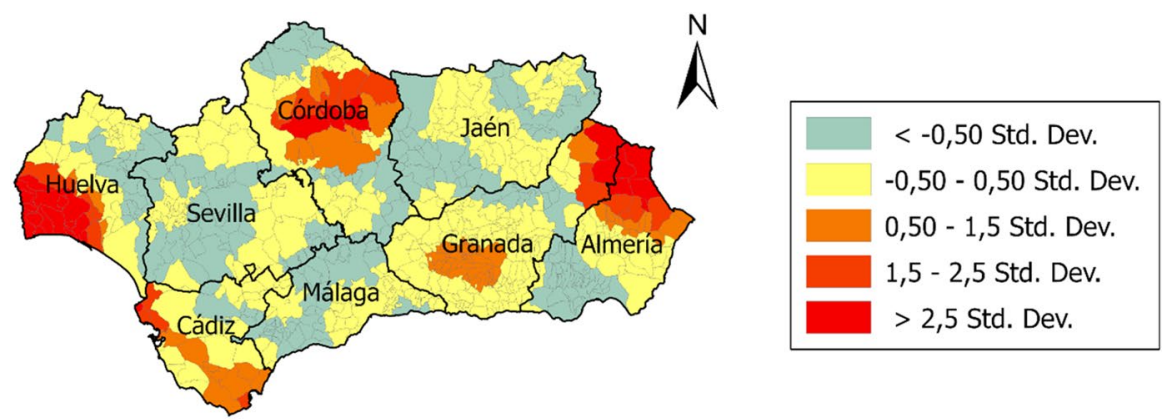

(a)
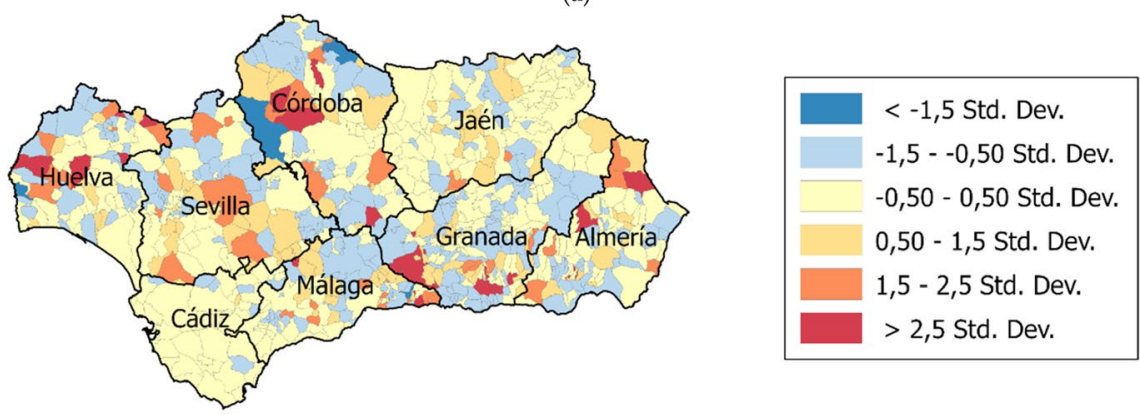

(b)
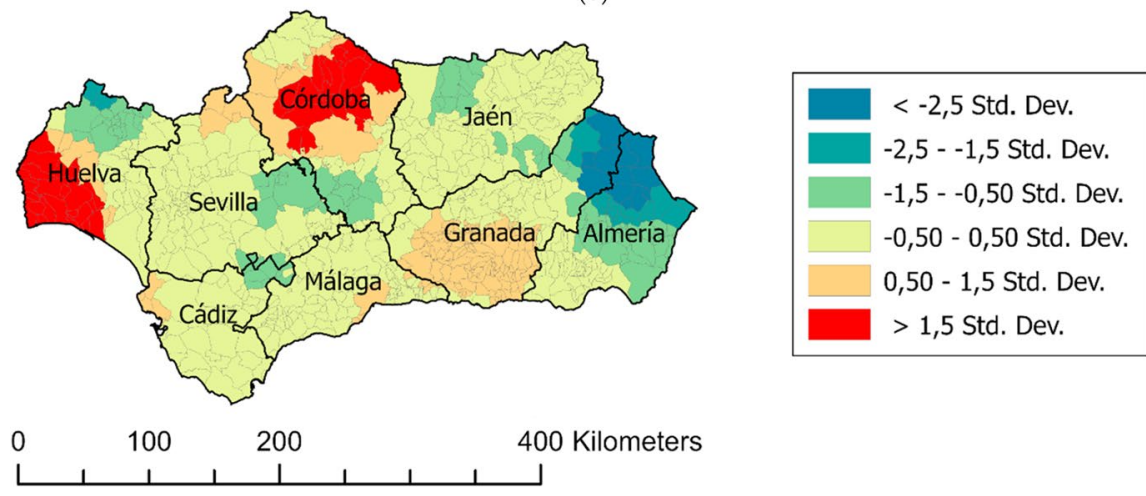

(c)

Fig. 5 Geographical weight regression. a $R^{2}$ local, b Residual, c Rurality 
providing training to isolated areas and dispensing advisory services addressing how start a business.

The results corroborate the previous research showing that spatial dependence influences entrepreneurship (Bishop, 2012; Espinoza et al., 2019; Plumber, 2010) while making other interesting contributions to regional government entrepreneurship policy.

Regarding the first hypothesis, the analysis reveals spatial dependence in CADE's support provided to labourers. Thus, business support is affected by what occurs in neighbouring municipalities as a common consequence of the creation of companies is the creation of related companies.

The results on clusters of hot and cold spots show that the CADEs serve as effective instruments of entrepreneurship policy. On the one hand, concentrations are lower in the areas positioned close to local capitals. This is likely attributable to the fact that the entrepreneurs in these areas can find other forms of support from the private sector and thus have less of a need for public support. On the other hand, the identification of clusters of municipalities in which support policies are less widespread can help reveal underlying problems and possible improvements for these policies in less-serviced areas.

The differences between ISP and IRB are an indicator of the viability of the projects supported in certain areas. For example, in the Sierra de Huelva, there is a greater concentration of supported projects and registered companies. This correspondence could be attributed to a greater effectiveness of CADE's workforce in that area, although it will be necessary to analyse the other factors that could explain this.

Concerning our second hypothesis, our results confirm that entrepreneurship support for SMEs has significantly intensified in Andalusia since the 2008 global financial crisis with CADEs following approaches to entrepreneurship support observed across the EU (2012). CADE support proved to be pivotal throughout the global financial crisis, in which credit restriction was one of the main impacts and has intensified since the crisis. This policy is in line with the academic literature that demonstrates the positive effects of entrepreneurship on the increase of employment, innovation and economic growth. However, the support activity of the CADEs has mainly been nonfinancial and likely due to limited financial resources for public administration during this period. Therefore, mentoring is an appropriate administrative support instrument in a context of crisis when there are restrictions on public spending.

This work is essential in Andalusia since it is one of the least developed regions within Spain and the EU despite its size and population importance (Micciché, 2018), as emphasized above.

Regarding the observed focus on rural and mountainous areas, CADEs have focused on entrepreneurs experiencing more difficulty in securing other forms of support due to their geographical locations. From these results, we can conclude that in focusing on rural and mountain areas, CADEs contribute to local development and the business fabric in these zones, where unemployment rates are largely higher and where threats of depopulation are apparent (Bergmann-Winberg, 2014; Bienkowska, 2013). According to Molinero (2019), the depopulation of rural spaces 
has crossed the limits of what is imaginable. There is a general concern regarding this issue, which extends throughout the European continent, the clearest example of which is Spain.

The demographic recovery of rural territories seems almost impossible in the short term, but if the outflow were to slow down, the foundations for a change in paradigm could be prepared (Molinero \& Alario, 2019). Recaño (2017) stated that the demographic sustainability of the heterogeneous group of rural municipalities in Spain hangs by a thread and poses a major demographic challenge that must take into account their great diversity when implementing public policies.

This research is limited in a number of ways. First, we do not have an entrepreneurial variable of the municipal level with which to compare to the number of projects supported by CADEs. Such a comparison would allow one to determine whether the number of entrepreneurs supported by CADEs follows the general trends of entrepreneurship observed in the region. Second, the rurality index explains only $13 \%$ of the supported entrepreneurship variable. Third, our model shows issues of heteroscedasticity that may obscure the results on the behaviours of specific regimes.

Proposed future research lines are as follows: (i) identify other explanatory variables that allow us to increase the percentage explained by supported enterprises and (ii) analyse in greater depth low concentration areas where support for entrepreneurship has less of an impact to identify any problems in the application of entrepreneurship policies and socioeconomic factors that may be shaping the limited impacts of these policies.

\section{Conclusions}

In this work, spatial analysis was used to identify the locations of the entrepreneurs supported by the regional government of Andalusia (Spain). The methodology used in the study allows us to identify the existence of spatial dependencies between variables. This confirms the first of the research hypotheses. Support for entrepreneurship by the Andalusia government is related to geographical location. No study has yet referred to the case of regional governments in Spain.

The analysis of the effectiveness of public policies is a relevant issue. Without evaluation, there is no possibility of improvement, and, as Lerner (2010) indicated, for every successful public intervention, there are many failed efforts that cost billions of dollars to taxpayers. Hence, evaluation is needed to avoid the misapplication of resources. Although Andalusia is an Objective 1 European region, few studies have analysed the effectiveness of the policies that support entrepreneurship adopted in this region. The confirmation of hypotheses two and three of this paper serves as an initial assessment of the scope and effectiveness of the entrepreneurship support of EDCs in Andalusia.

On the one hand, we conclude that public support for entrepreneurship intensified in the years of the economic crisis. The support to which we refer is not the provision of financial resources but nonmonetary support such as mentoring. This is especially important in the context of budget constraints. On the other hand, it is 
corroborated that public support for entrepreneurship has been concentrated in rural areas where the level of need is greatest.

The results of this work confirm the important role of public support for entrepreneurship during a period of crisis. Public administrations are going to face a new economic crisis. Public policy to support entrepreneurship will be one of the most important public policies to recover employment and the economy after the global crisis of COVID-19.

Supplementary Information The online version contains supplementary material available at https://doi. org/10.1007/s12061-021-09418-y.

Acknowledgements The authors thank Andalucía Emprende (Junta de Andalucía Gobierno) for provided the data in order to carry out this research.

Funding This study was no funded.

\section{Declarations}

Conflict of interest The authors declare that they have no conflict of interest.

\section{References}

Ács, Z. J., Szerb, L., Ortega-Argilés, R., Aidis, R., \& Coduras, A. (2015). The regional application of the Global Entrepreneurship and Development Index (GEDI): The case of Spain. Regional Studies, 49(12), 1977-1994.

Aernoudt, R. (2004). Incubators: Tool for entrepreneurship? Small Business Economics, 23, 127. https:// doi.org/10.1023/B:SBEJ.0000027665.54173.23

Anselin, L. (2001). Spatial econometrics. In B. H. Baltagi (Ed.), A companion to theoretical econometrics (pp. 310-331). Blackwell.

Anselin, L., Syabri, I., \& Kho, Y. (2006). GeoDa: An introduction to spatial data analysis. Geographical Analysis, 38(1), 5-22. https://doi.org/10.1111/j.0016-7363.2005.00671

Aparicio, S., Urbano, D., \& Audretsch, D. (2016). Institutional factors, opportunity entrepreneurship and economic growth: panel data evidence. Technological Forecasting y Social Change, 102, 45-61. https://doi.org/10.1016/j.techfore.2015.04.006

Arshed, N., Carter, S., \& Mason, C. (2014). The ineffectiveness of entrepreneurship policy: Is policy formulation to blame? Small Business Economic, 43(3), 639-659. https://doi.org/10.1007/ s11187-014-9554-8

Anton, S. G., \& Onofrei, M. (2016). Public policies to support entrepreneurship and SMEs. Empirical evidences from Romania. Transylvanian Review of Administrative Sciences, 47, 5-19.

Auchincloss, A. H., Gebreab, S. Y., Mair, C., \& Diez Roux, A. V. (2012). A review of spatial methods in epidemiology, 2000-2010. Annual Review of Public Health, 33(1), 107-122. https://doi.org/10. 1146/annurev-publhealth-031811-124655

Audretsch, D. B., \& Beckmann, I. A. M. (2007). From small business to entrepreneurship policy. In D. Audretsch, I. Grilo, \& A. R. Thurik (Eds.), Handbook of research on entrepreneurship policy (pp. 36-51). Edward Elgar Publishing Limited.

Audretsch, D. B., Heger, D., \& Veith, T. (2015). Infrastructure and entrepreneurship. Small Business Economics, 44(2), 219-230.

Bailey, T. C., \& Gatrell, A. C. (1995). Interactive spatial data analysis (Vol. 413). Longman Scientific and Technical Essex.

Bergmann-Winberg, M. L. (2014). Social and political entrepreneurship: Ways and means to develop sparsely populated regions? In A. Lundström, C. Zhou, Y. von Friedrichs, \& E. Sundin (Eds.), Social Entrepreneurship. International studies in entrepreneurship. (Vol. 29). Springer. 
Bienkowska, W. (2013). Activities of local authorities in promoting entrepreneurship in Poland. Economic Science for Rural Development, 32, 26-31.

Bishop, P. (2012). Knowledge, diversity and entrepreneurship: A spatial analysis of new firm formation in Great Britain. Enterpreneurship and Regional Development, 24(7-8), 641-660. https://doi.org/10. 1080/08985626.2011.617786

Brunsdon, C., Fotheringham, A. S., \& Charlton, M. E. (1996). Geographically weighted regression: A method for exploring spatial nonstationarity. Geographical Analysis, 28(4), 281-298.

Chasco, C. (2013). GeoDaSpace: A resource for teaching spatial regression models. Rect@, (4), 119.

Cliff, A. D., \& Ord, J. K. (1969). The problem of spatial autocorrelation. In London Papers in Regional Science (pp. 25-55). Retrieved from http://www.sciepub.com/reference/18110

Cobo-Soler, S., Fernández-Alcantud, A., López-Morales, J. M., \& Santamaría-García, M. (2018). Public support for entrepreneurship, human capital and talent in the context of Spanish tourism. Investigaciones Regionales - Journal of Regional Research, 42, 53-74.

Eklund, J., Levratto, N., \& Ramello, G. B. (2020). Entrepreneurship and failure: Two sides of the same coin? Small Business Economic, 54, 373-382. https://doi.org/10.1007/s11187-018-0039-z

Espinoza, C., Mardones, C., Sáez, K., \& Catalán, P. (2019). Entrepreneurship and regional dynamics: The case of Chile. Journal Entrepreneurship and Regional Development. https://doi.org/10.1080/ 08985626.2019 .1565421

Esri Inc. (2020). ArcGIS Pro (Version 2.5).

EU Commission. (2012). Entrepreneurship 2020 Action Plan. Retrieved from https://eur-lex.europa.eu/ LexUriServ/LexUriServ.do?uri=COM:2012:0795:FIN:en:PDF

EU Parliament, (2013). Directive 2013/34/EU Of the European Parliament and of the Council of 26 June 2013. Retrieved from https://eur-lex.europa.eu/legal-content/EN/TXT/PDF/?uri=CELEX:32013 L0034\&from $=$ ES

Fritsch, M., \& Storey, D. J. (2014). Entrepreneurship in a regional context: Historical roots, recent developments and future challenges. Regional Studies, 48(6), 939-954.

Fritsch, M., \& Wyrwich, M. (2014). The long persistence of regional levels of entrepreneurship: Germany, 1925-2005. Regional Studies, 48(6), 955-973.

Fotheringham, A. S. (2002). Geographically weighted regression: the analysis of spatially varying relationships. Wiley.

García-Alonso, C. R., Pérez-Naranjo, L. M., \& Fernández-Caballero, J. C. (2014). Multiobjective evolutionary algorithms to identify highly autocorrelated areas: The case of spatial distribution in financially compromised farms. Annals of Operations Research, 219(1), 187-202. https://doi.org/10. 1007/s10479-011-0841-3

Getis, A., \& Ord, J. K. (1992). The analysis of spatial association by use of distance statistics. Geographical Analysis, 24, 189-206. https://doi.org/10.1111/j.1538-4632.1992.tb00261.x

Godtfredsen, L. R. (2007). Entrepreneurship in Slovenia: Assessing the impact of public policy. Communist Economies and Economic Transformation, 8(3), 411-425.

Goerlich, F. J., Reig, E., \& Cantarino, I. (2016). Construcción de una tipología rural/urbana para los municipios españoles. Journal of Regional Research, 35, 151-173.

Greene, W. H. (2018). Econometric analysis (8th ed.). Pearson.

Guerra, G., \& Patuelli, R. (2014). The influence of role models on immigrant self-employment: A spatial analysis for Switzerland. International Journal of Manpower, 35(12), 187-215. https://doi.org/10. 1108/IJM-08-2013-0200

INE. (2015). INEbase/Mercado laboral/Actividad, ocupación y paro. Retrieved April 30, 2016, from http://www.ine.es/dyngs/INEbase/es/categoria.htm?c=Estadistica_Pandcid=1254735976595

De Jorge-Moreno, J. (2017). Influence of entrepreneurship on economic growth and efficiency: Importance of institucional quality and social innovation from an international perspective. Revista De Economía Mundial, 46, 137-162.

Junta de Andalucía. (2014). Programa de Desarrollo Rural de Andalucía 2014-2020, 2013 (Versión 10), 289. https://doi.org/10.1017/CBO9781107415324.004.

Junta de Andalucía. (2018). Ley 3/2018, de 8 de mayo, Andaluza de Fomento del Emprendimiento. España.

Katimertzopoulos, F. \& Vlados, C. (2017). Local support mechanisms for entrepreneurship: The approach of local development and innovation institutions. Retrieved from https://papers.ssrn.com/ sol3/papers.cfm?abstract_id $=3002388$ 
Ladeira, F. M. B., \& Machado, H. V. (2013). Social Entrepreneurship: A reflection for adopting public policies that support the third sector in Brazil. Journal of Technology Management and Innovation, 8, 188-196. https://doi.org/10.4067/S0718-27242013000300017

Lerner, J. (2010). The future of public efforts to boost entrepreneurship and venture capital. Small Business Economics, 35, 255-264. https://doi.org/10.1007/s11187-010-9298-z

Mann, H. B., \& Whitney, D. R. (1947). On a test of whether one of two random variables is stochastically larger than the other. The Annals of Mathematical Statistics, 18(1), 50-60. https://doi.org/10.1214/ aoms/1177730491

Maas, C., Salinas-Perez, J. A., Bagheri, N., Rosenberg, S., Campos, W., Gillespie, J. A., \& SalvadorCarulla, L. (2019). A spatial analysis of referrals to a primary mental health programme in Western Sydney from 2012 to 2015. Geospatial Health, 14, 204-210. https://doi.org/10.4081/gh.2019.773

Mckevitt, D., \& Marshall, D. (2015). The legitimacy of entrepreneurial mentoring. International Journal of Entrepreneurial Behaviour and Research. https://doi.org/10.1108/IJEBR-05-2014-0089

Micciché, R. (2018). Política de cohesión. Bruselas. https://doi.org/10.2776/44725

Molinero, F. (2019). El espacio rural de España: Evolución, delimitación y clasificación. Cuadernos Geográficos, 58, 1-38.

Molinero, F., \& Alario, M. (2019). Ante el reto de la despoblación de la España interior y sus diferencias regionals. In: Cejudo, E. and Navarro, F. (eds.). Despoblación y transformaciones sociodemográficas de los territorios rurales: los casos de España, Italia y Francia, Perspectives on Rural Development 3, pp. 41-69

Moran, P. (1950). Notes on continuous stochastic phenomena. Biometrika, 37(1/2), 17-23. Retrieved from https://www.jstor.org/stable/2332142

Mustafa-Topxhiu, R. (2012). The role of entrepreneurship and enterprises for local economic development. Academicus - International Scientific Journal, 5, 96-107.

OECD. (2009). The impact of the global crisis on SME and entrepreneurship financing and policy responses [Online]. Retrieved from http://www.oecd.org/industry/smes/43183090.pdf

OECD. (2010). Assessment of government support programmes for SMEs' and entrepreneurs' access to finance in the global crisis [Online]. Retrieved from http://www.oecd.org/cfe/smes/Assessment_ Government_Support_Programmes.pdf

OECD. (2012). Financing SMEs and Entrepreneurs 2012: An OECD Scoreboard, 2012 [Online]. Retrieved from http://www.oecd-ilibrary.org/industry-and-services/financing-smes-and-entreprene urship_9789264166769-en

OECD and European Commission. (2017). The missing entrepreneurs: Policies for inclusive entrepreneurship in Europe [Online]. Retrieved from http://www.oecd.org/industry/the-missing-entreprene urs-2017-9789264283602-en.htm

Plummer, L. A. (2010). Spatial dependence in entrepreneurship research: Challenges and methods. Organizational Research Methods, 13(1), 146-175.

Recaño, J. (2017). La sostenibilidad demográfica de la España vacía. Perspectives Demografiques, 7, 1-4.

Ribeiro-Soriano, D., \& Galindo-Martín, M. A. (2012). Government policies to support entrepreneurship. Entrepreneurship and Regional Development, 24(9-10), 861-864.

Rodero-Cosano, M. L., Salinas-Perez, J. A., Gonzalez-Caballero, J. L., Garcia-Alonso, C. R., LagaresFranco, C., \& Salvador-Carulla, L. (2014). The relationships between depression spatial clusters and mental health planning in Catalonia (Spain). In: Lecture Notes in Computer Science (including subseries Lecture Notes in Artificial Intelligence and Lecture Notes in Bioinformatics) (vol. 8582 LNCS, pp. 438-447). Springer International Publishing. https://doi.org/10.1007/978-3-319-09147$1 \_32$

Rodríguez, G. I., \& Tarazona, O. (2015). Unidades de emprendimiento bajo un estudio de eficiencia relativa. Revista Facultad De Ciencias Económicas: Investigación y Reflexión, 2, 149-162.

Salinas Pérez, J. A. (2012). Análisis espacial de la distribución en el territorio de variables sanitarias y socioeconómicas mediante técnicas de inteligencia artificial y sus aplicaciones en la planificación sociosanitaria de la salud mental. Universidad de Córdoba.

Shane, S. (2009). Why encouraging more people to become entrepreneurs is bad public policy. Small Business Economics, 33(2), 141-149. https://doi.org/10.1007/s11187-009-9215-5

Shekhar, S., Evans, M. R., Kang, J. M., \& Mohan, P. (2011). Identifying patterns in spatial information: A survey of methods. Wiley Interdisciplinary Reviews: Data Mining and Knowledge Discovery, 1(3), 193-214. https://doi.org/10.1002/widm.25 
Skica, T., Bem, A. \& Daszyńska Żygadło, K. (2014). The role of local government in the process of entrepreneurship development. Financial Internet Quarterly, “e-Finance," 9 (4): 1-24. Retrieved from https://www.econstor.eu/handle/10419/147080

Tobler, W. R. (1970). A computer movie simulating urban growth in the detroit region. Economic Geography, 46(sup1), 234. https://doi.org/10.2307/143141

United Nations. (2014). Entrepreneurship for development. Retrieved from: https://unctad.org/meetings/ en/SessionalDocuments/a69d320_en.pdf

Wakefield, J., Kelsall, J. E., \& Morris, S. E. (2000). Clustering, cluster detection, and spatial variations in risk. Oxford University Press.

Wilbanks, J. E. (2015). Mentoring and entrepreneurship: Examining the potential for entrepreneurship education and for aspiring new entrepreneurs. Small Business Strategy, 23, 93-101.

Publisher's Note Springer Nature remains neutral with regard to jurisdictional claims in published maps and institutional affiliations.

\section{Authors and Affiliations}

\section{Maria Luisa Rodero-Cosano ${ }^{1}$ (i) - Araceli de los Ríos-Berjillos ${ }^{2}$. Salud Millán-Lara ${ }^{3}$ Y Yolanda Muñoz-Ocaña ${ }^{1}$}

Maria Luisa Rodero-Cosano

mlrodero@uloyola.es

Salud Millán-Lara

smillan@uloyola.es

Yolanda Muñoz-Ocaña

yolandam@uloyola.es

1 Deparment of Quantitative Methods, Universidad Loyola Andalucía, Córdoba, Spain

2 Deparment of Business Management, Universidad Loyola Andalucía, Campus Córdoba, C/Escritor Castilla Aguayo, 4, 14004 Córdoba, Spain

3 Deparment of Financial Economic and Accounting, Universidad Loyola Andalucía, Córdoba, Spain 